\title{
Tree-ring analysis of teak (Tectona grandis L. f.) from Western Ghats of India as a tool to determine drought years
}

\author{
M. S. Deepak ${ }^{1 *}$, Satish Kumar Sinha ${ }^{2}$ and R. Vijendra Rao ${ }^{1}$ \\ ${ }^{1}$ Dendrochronology Laboratory, Wood Properties and Uses Division, \\ Institute of Wood Science\& Technology, Bangalore 560003, India; ${ }^{2}$ Forest Products and \\ Utilization-Division, ASPEE College of Horticulture and Forestry, Navsari Agricultural \\ University, Navsari, Gujarat 396450, India
}

\begin{abstract}
Tree-ring analysis of teak (Tectona grandis L.f.) carried out from two different sites in Western Ghats of India is reported in this paper. Teak has distinct, datable and climatic sensitive growth rings which are formed annually. Growth rings are not only cross-matching even within the radius of a tree but also between trees growing at both the sites. The tree-ring chronology of teak and climatic data revealed that there are several alternating periods of low and high to very high rainfall years. The common low rainfall years at two sites matched with the most of drought years of India. It has been found to have good potential to know rainfall pattern, mostly the drought years.
\end{abstract}

Keywords: Growth rings, climate, dendrochronology, cross-dating, dendroclimatology.

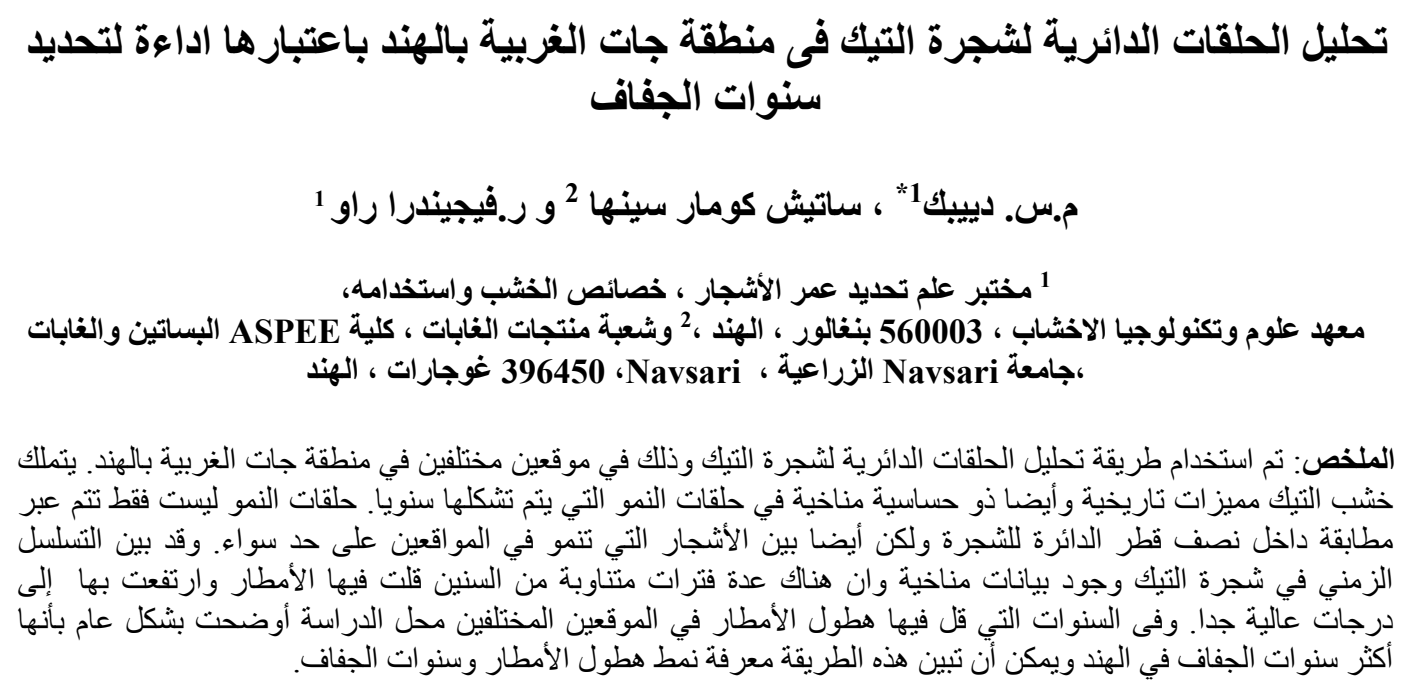

*Corresponding Author, Email: deepak.ms@rediffmail.com 


\section{Introduction}

Growth rings of tree are important to understand the events like fire, insect attack, climate change and so on, that happened in the past. The study of this science is known as dendrochronology. Growth rings are distinct in trees of temperate regions. Unlike trees of temperate regions, most of tropical trees have been excluded from dendrochronology studies because of lack of seasonality and the absence of a clear dormancy of the cambial activity failing to produce distinct growth rings. However, Brandis (1879) pointed out growth rings in several Indian tropical trees in relation to mensuration studies and reported annual growth rings in teak. Gamble (1902) studied growth rings in a large number of tropical trees as annual rings. Even in species where the rings were distinct, age determination by counting their growth rings was considered unreliable (Coster, 1927). It is estimated that about twenty five percent of the total number of tree species produce growth rings (Chowdhury, 1939, 1940).

The science of reconstructing past climate by use of tree-rings is known as dendroclimatology which is a branch of the more general discipline of dendrochronology (Fritts, 1976). After Chowdhury's initial work on growth ring formation in relation to climate, limited work has been carried out in teak from the point of view of dendroclimatology at several sites of India viz., from moist deciduous forest in Thane, Maharashtra (Pant and Borgaonkar,1983; Ramesh et al.,1989; Bhattacharyya et al.,1992), dry deciduous forest in Korzi, Andhra Pradesh (Yadav and Bhattacharyya, 1996), Western ghats of Kerala (Bhattacharyya et al., 2007; Borgaonkar et al., 2010), upper Narmada river basin in Central India (Wood, 1996) and dry deciduous forests of Madhya Pradesh (Shah et al., 2007;
Somaru et al., 2008) and outside India viz., from Thailand (Pumijumnong and Park, 1999; Buckley et al., 2007) and Indonesia (D’Arrigo et al., 1989, 2006). These exploratory studies revealed that tree rings of teak could be valuable proxy data for dendroclimatic analysis, especially monsoon precipitation. Although Western Ghats of India is also well known for being one of the best teak growing sites in which Shimoga and Dandeli are selected for the present study. Climate of the Western Ghats is dominated by the tropical monsoon. It is an important site for the dendroclimatic analysis because monsoon rainfall in this region varies from place to place. Some areas to the north in Western Ghats while receiving heavier rainfall are followed by long dry spells, while regions closer to the equator receiving less annual rainfall, have rain spells lasting almost the entire year (Ranjit, 2007). No detailed treering analysis has been reported so far on this tree species in this area. In this paper, an attempt has been made to analyze the growth rings of teak (Tectona grandis) in relation to rainfall pattern, mostly the drought years at two sites of Western Ghats.

\section{Material and Methods}

\section{Study area and sample collection}

Ten increment core samples were collected using increment borer at DBH of teak trees from Shimoga in October 2007 (13 $56^{\prime} \mathrm{N}$ latitude and $75^{\circ} 38^{\prime} \mathrm{E}$ longitude) and ten cross-sectional discs were collected from Dandeli teak plantation of Haliyal forest division in April 1999 from the base of felled trees at Yellapur Karnataka $\left(15^{\circ} 16^{\prime} 0 \mathrm{~N}\right.$ latitude and $74^{\circ}$ $37^{\circ} 0 \mathrm{E}$ longitude.) for tree-ring analysis (Figure 1). 


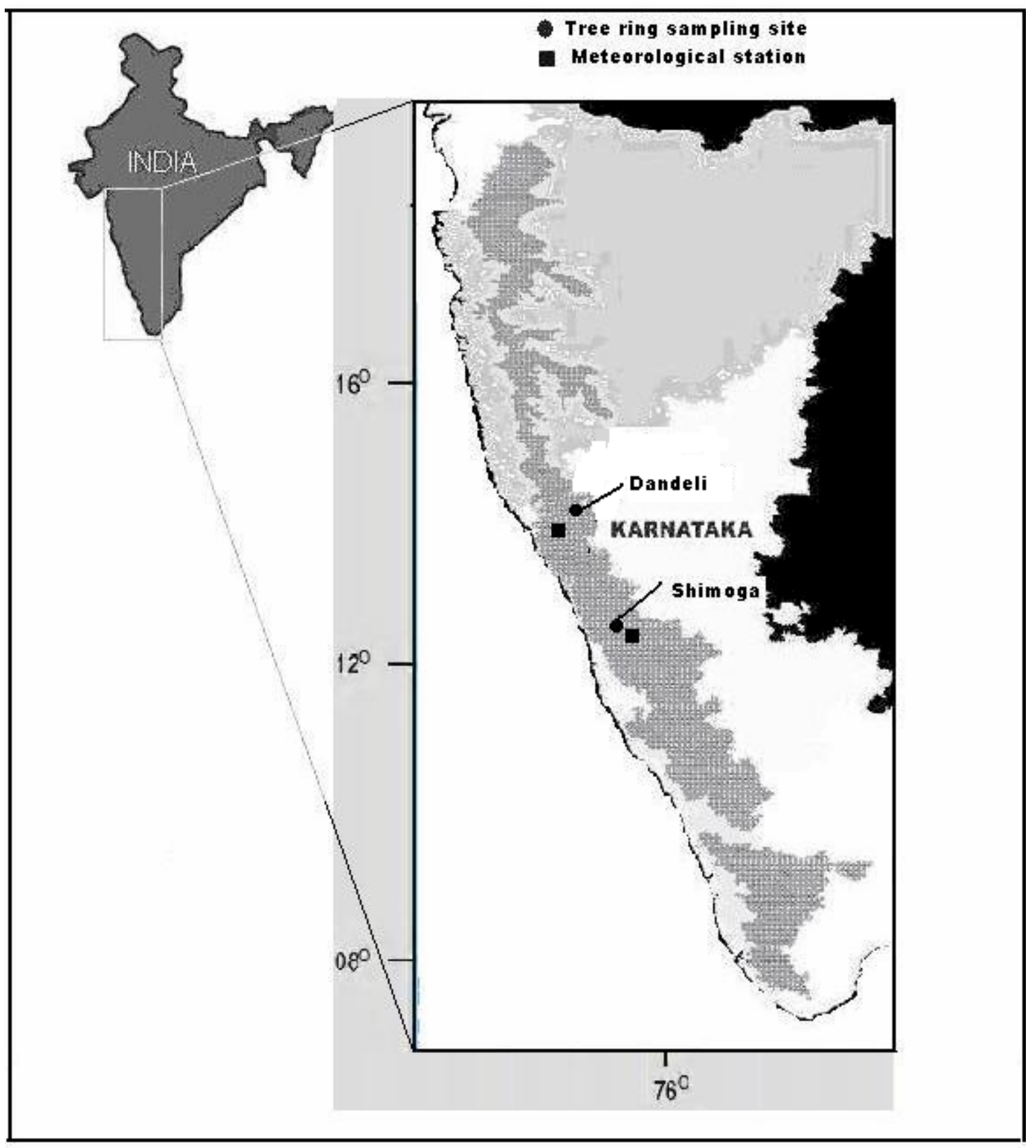

Figure 1. Location of tree ring sampling site and meteorological station.

\section{Tree-ring data}

The surfaces of twenty samples were sanded with different grades of sand papers to expose the growth rings and prepare the wood for the microscopic analysis. In the case of discs from Dandeli two radial strips of $1.5 \mathrm{~cm}$. width were cut from opposite side of discs which includes all the rings from pith to bark. The rings of each sample were dated to the calendar year of its formation after using cross-matching technique of skeleton-plot method (Stokes and Smiley, 1968). The ring-widths were measured to the nearest $0.01 \mathrm{~mm}$ under a Leica stereozoom microscope with a linear stage 
(Velmex) interfaced with a computer system to record the measurements. These measurements and dates were re-checked using the computer program COFECHA (Holmes, 1983) for any error in the measurement or dating of the samples. The average raw ring-width and its age related trend in teak samples from both the sites are shown in Figures 2 and 3.

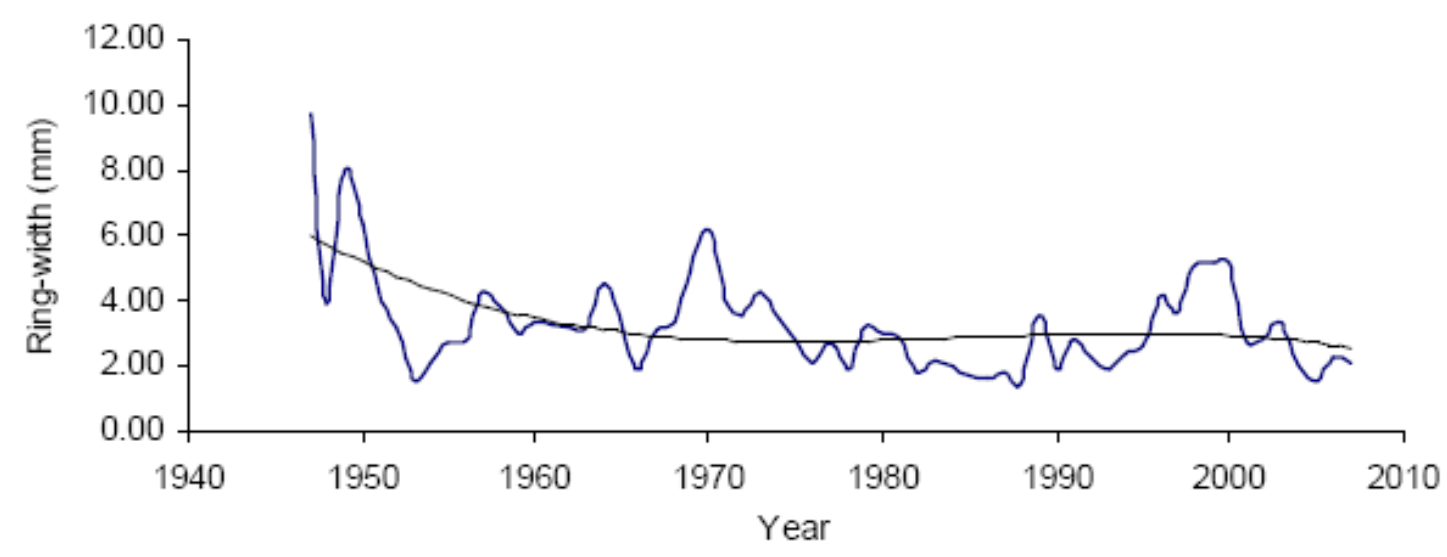

Figure 2. Average ring- width curve of Teak (Tectona grandis) from Shimoga showing agerelated trend.

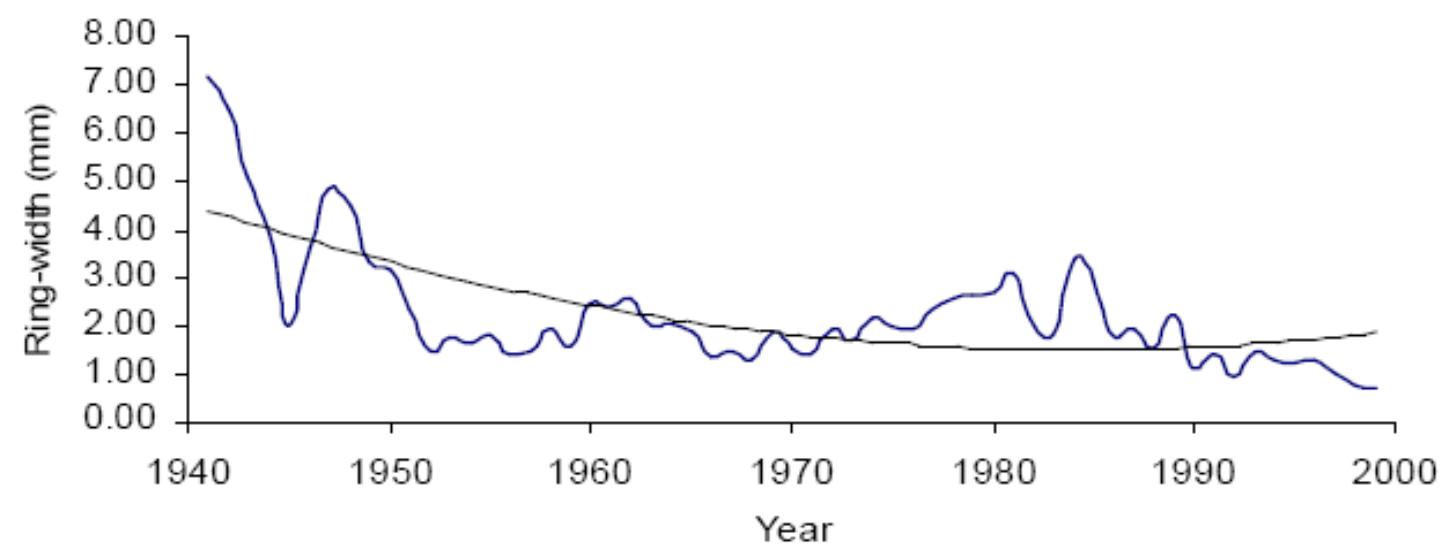

Figure 3. Average ring- width curve of Teak (Tectona grandis) from Dandeli showing agerelated trend.

Trees growing in a natural environment are influenced by small variations in their environmental conditions. Such variations are recorded in trees by one way or the other with the same or different intensities (Figure 4). The major parameters which affect tree growth are increasing tree age, climatically related signals common to all trees at a site, endogenous disturbances limited to individual trees due to competition among the trees at the same site, exogenous disturbances common to the trees from the same stand which may be caused by fire, insect, disease, pollution, logging, and finally a random growth signal unique to each 
tree. Standardization is a statistical procedure to extract useful signals (e.g. climatic signal) from trees (Cook, 1987) and is an important task in dendroclimatic studies.

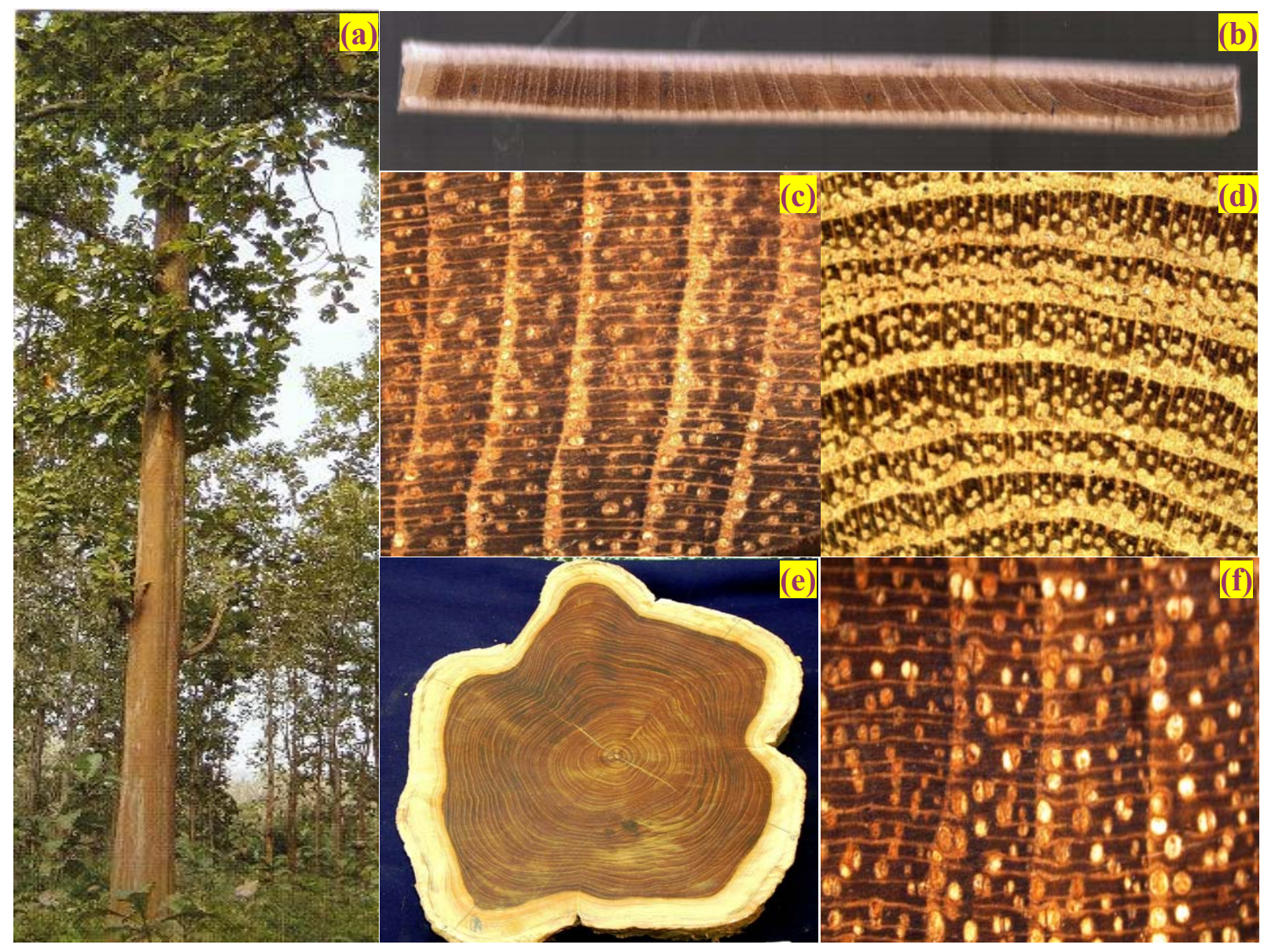

Figure 4. (a) The teak tree in natural habitat, (b)-(e) Different plates showing growth rings.

Standardization of tree-ring width series of two sites, Dandeli and Shimoga, has been done by the computer program ARSTAN (Cook, 1985; Holmes, 1992). The program provides various options of detrending such as a negative exponential, linear regression, cubic spline smoothing with detailed statistics of each series and chronology. In our analysis, the negative exponential method was found to be most appropriate for smoothing age trends in width values. Indices of each series were derived by dividing the raw ring width by the corresponding smooth value for each year. Most of the ring-width series show high autocorrelation. We have used autoregressive modelling which removes an autocorrelation structure in the series and enhances the common signal. All individual index series were averaged over the site to form a site tree-ring width index chronology.

\section{Statistical analysis}

The statistical performance of ringwidth-index chronologies from two sites is given in Table 1. Tree-ring chronologies having a high mean sensitivity, standard deviation, mean correlation (common variance), signal-to-noise ratio (SNR) and a low persistence (auto-correlation) are supposed to be suitable for climatic reconstructions (Fritts, 1976). All the ringwidth series before standardization show a 
high autocorrelation which is the linkage of each value with the immediately preceding value in the series. The high autocorrelation and low mean sensitivity indicate the presence of low-frequency variance in the series. For dendroclimatic studies, however, the high-frequency variance is of more interest. After standardization autoregressive modelling removes the high autocorrelation structure in the series and enhances the common signal. Moderately high value of standard deviation, mean sensitivity, common variance (mean correlation among all the tree samples) and low autocorrelation structure indicate the high dendroclimatic potential of these two chronologies. The mean sensitivity (MS), which is the measure of the relative difference in the width from one ring to the next, is moderately high for both chronologies. Its theoretical range is zero to two. SNR $>1$ indicates the more common useful signal than the residual noise. The value of SNR is moderately high for both chronologies with highest SNR of Dandeli chronology.

Table 1. Selected statistics of tree-ring index chronologies of Tectona grandis L. at Dandeli and Shimoga (India).

\begin{tabular}{lll}
\hline & Dandeli & Shimoga \\
\hline Chronology time span & AD 1941-1999 & AD 1947-2007 \\
Number of trees (radii) & $10(19)$ & $10(10)$ \\
Mean tree-ring width (mm) & 2.15 & 3.10 \\
Standard deviation & 0.320 & 0.210 \\
Mean sensitivity & 0.228 & 0.254 \\
Autocorrelation order 1 & 0.023 & 0.018 \\
Common interval time span & $1944-1999$ & $1960-2007$ \\
Number of trees (radii) & $9(18)$ & $8(8)$ \\
Mean correlation between trees & 0.25 & 0.48 \\
Signal-to-noise ratio & 5.90 & 2.69 \\
Expressed population signal & 0.87 & 0.74 \\
Variance explained \% & 30.91 & 64.85 \\
in first eigenvector & & \\
\hline
\end{tabular}

The Expressed Population Signal (EPS) indicates the usefulness of the chronologies for climate reconstruction. When the common signal is expressed as a fraction of total chronology variance, it is termed as agreement with population chronology or Expressed Population Signal (EPS) (Wigely et al., 1984). EPS decides the agreement of a sample chronology with population chronology. Wigely et al. (1984) suggest that chronologies with EPS $\geq 0.85$ can be accepted as reliable chronology for dendroclimatic analysis. The common variance is a mean of the correlation coefficients of all pairwise combinations of ring-width index series over the common interval period. This value indicates the variance owing to the common forcing factor which might be a climatic effect experienced by all trees over a wide area. With our two chronologies a climatic reconstruction is not possible as data is for a short period.

\section{Climatic data}

The climatic data (annual rainfall) nearest to the tree ring sampling site, available from Dandeli and Shimoga 
meteorological stations, have been taken up for ring-width analysis of teak. This record extends from AD 1941-1999 and AD 1947- 2007 for Dandeli and Shimoga regions respectively.

\section{Results and Discussion}

Tectona grandis is a ring porous to semi ring porous wood. Rings are clear and distinguished by the pore size. These are usually annual but false rings also occur in saplings and mature trees (Chowdhury, 1964). False rings are those rings which do not produce any complete or continuous growth marks all around the circumference. It was earlier reported that false rings were formed in several teak trees due to physiological disturbances and insect defoliation (Chowdhury, 1964; Priya and Bhat, 1998). In the present study, it was observed one or two false rings occurring in a few samples, but these were easily traceable during cross-dating when ring-width was measured in two different directions along the diameter of each sample. Cross-dating is the primary guiding principle in dendrochronology, and concerns the matching of patterns of ring widths from one tree with corresponding patterns for the same years from another tree. After cross-dating, standardization of tree-ring width series of two sites was carried out to eliminate longterm variables which have been caused by bio-ecological factors such as tree age and microsite differences.

\section{Tree growth - climate relationship}

Rainfall and temperature are the main decisive factors for tree growth. To understand its role in tree growth, the standardized ring-width-index chronologies of two sites was correlated with the annual rainfall of corresponding sampling sites. The narrow growth rings in teak have been found to match with the low rainfall years. Earlier tree ring studies of teak from central Java region showed that rainfall of the previous year's rainy season and during the usual onset month of the current year's rainy season has significant relation to teak growth (D'Arrigo et al., 1989). This indicates that the moisture balance of the soil before the beginning of the next year growing season is important for teak growth. Similar observation was also found by Ramesh et al. (1989) by using the stable isotope ratio of annual rings contains considerable potential for rainfall reconstruction. Figure 5 and 6 shows the teak tree-ring chronologies of Shimoga and Dandeli regions and its monsoon rainfall respectively.

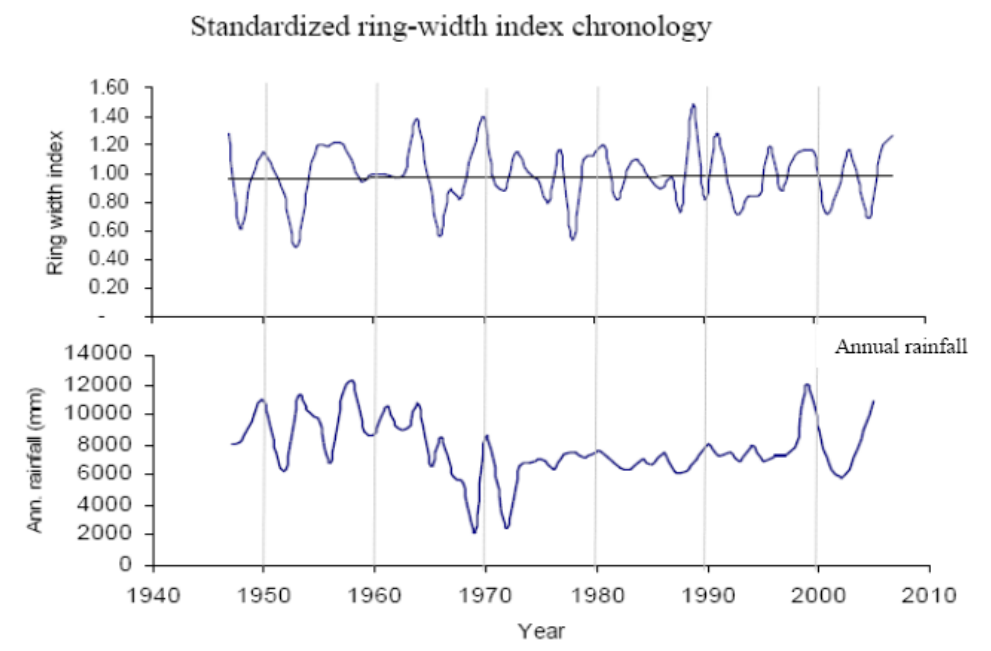

Figure 5. Ring width index chronology of Teak (Tectona grandis) from Shimoga after removal of age-related trend by standardization and annual rainfall at Shimoga together to show the correlation between tree growth and rainfall. 


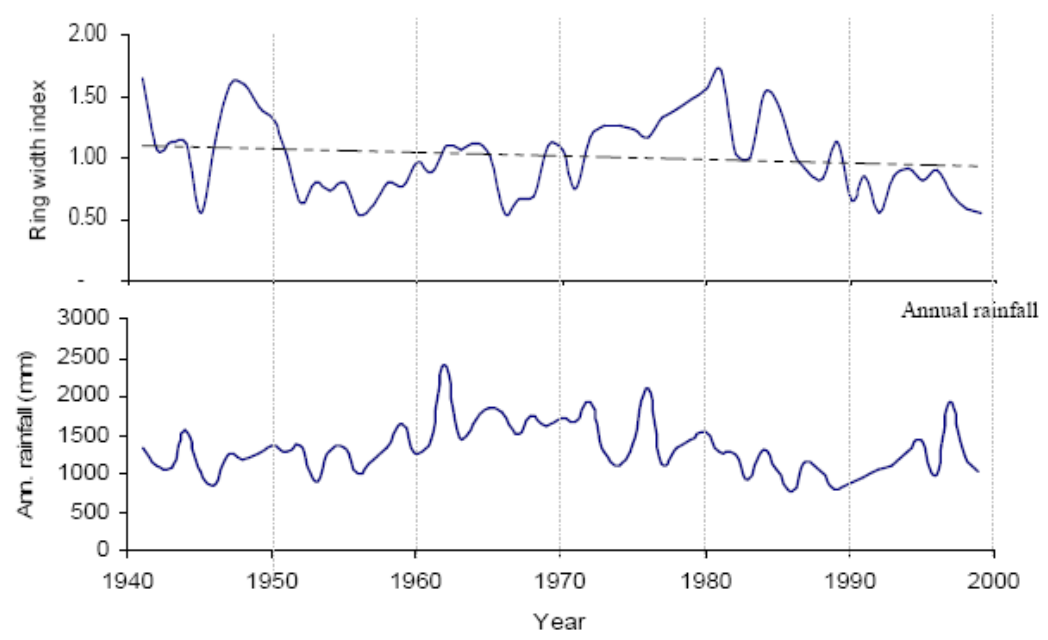

Figure 6. Ring width index chronology of Teak (Tectona grandis) from Dandeli after removal of age-related trend by standardization and annual rainfall at Dandeli together to show the correlation between tree growth and rainfall.

Every year in a specific time period, the climate of a location is different. Some years have below average rainfall, some have average or above average rainfall. Due to the phenomenon of climate change affecting India, such variability would have an impact on agriculture. As a result of variability, the hydrological cycle is likely to be altered and severity of droughts and intensity of floods in various parts of India is likely to increase. When an area receives less than $750 \mathrm{~mm}$ rainfall in a year it is called low rainfall year or drought year and when annual rainfall is between $1126 \mathrm{~mm}$ to $2000 \mathrm{~mm}$ or above $2000 \mathrm{~mm}$ it is called high to very high rainfall year (Anonymous, 2009a) The simple correlation between average ringwidth-index chronologies of both the sites and annual rainfall of corresponding sampling sites is greater than 0.4 which is significant at 0.05 level. The tree ring chronology and climatic data revealed that there are several alternating periods of low and high to very high rainfall years. The markedly low rainfall years are: 1951, 1965, 1966, 1971, 1972, 1977, 1978, 1982, 1988 and 1992 and relatively high to very high rainfall years are: 1950, 1955, 1958, 1962, 1970, 1981, 1998 are common years matched with the tree-ring-index chronology from both the sites (Figure 5 and 6). The above low rainfall years also matched with the most of drought years of India (Anonymous, 2009b). The previous year's rainfall of the region is also equally significant for current year's tree growth, the spell of good rainy years reflects the normal growth of teak. Rest of the unmatched years of tree ring chronology and climatic data may be due to the carry over effect of moisture balance which acts as a booster for the subsequent growing seasons. On the other side, continuous low rainfall years carry over the lack of moisture, not sufficient for the normal growth resulting in group of narrow rings. Other ring- porous tree like Lagerstroemia lanceolata, Toona ciliata, Morus alba etc. from similar sites are worth investigating tree ring analysis.

\section{Conclusion}

The present study revealed that Tectona grandis of tropical region of Western Ghats of India has good potential for dendroclimatic analysis, especially to reconstruct past variations of rainfall. Teak has been found to have a good potential for reconstruction of drought years. The low rainfall years found by tree ring 
chronologies of teak are matched with most of the drought years of India. The potentiality of trees other than teak in tropical forests will also be important for tree ring analysis, especially if it is datable. Even if one or two potential species are found for dendroclimatic study from each of the diversified tropical forests it would be great significance in the study of various aspects of climate changes from the vast part of Indian subcontinent.

\section{Acknowledgement}

The present paper represents part of a research project sponsored by the Ministry of Environment and Forest, Govt. of India and the first two authors are thankful to the ministry for award of SRF under the project entitled "Investigations on tree ring analysis of certain species of Western Ghats to monitor climate changes and its relevance to wood quality". The authors are thankful to S.C. Joshi, Director and S.C.Gairola, Group Coordinator Research for their encouragement. Thanks are also due to H.P. Borgaonkar, IITM, Pune for assisting in tree-ring sample analysis.

\section{References}

Anonymous. 2009a. Drought years of India. Vijaya Karnataka newspaper (in Kannada) dated 20 August.

Anonymous. 2009b. Manual for drought management; Department of Agriculture and Cooperation, Dept. of Agriculture, Government of India. New Delhi. pp. 21-146.

Bhattacharyya, A., D. Eckstein, S. K. Shah and V. Chaudhary. 2007. Analyses of climatic changes around Parambikulum, South India, based on early wood mean vessel area of teak. Curr. Sci. 93:1159-1164.

Bhattacharyya, A., R. R. Yadav, H. P. Borgaonkar and G. B. Pant. 1992. Growth- ring analysis of Indian tropical trees: dendroclimatic potential. Curr. Sci. 62:736-740.
Borgaonkar, H. P., A. B. Sikder, Somaru Ram and G. B. Pant. 2010. El Niño and related monsoon drought signals in 523-year-long ring width records of teak (Tectona grandis L. f.) trees from south India. Palaeo-Geogra. Climato. Eoeco. 285:74-84.

Brandis, D. 1879. Memorandum of the rate of growth of teak. Indian Forest. pp. 4.

Buckley, B. M., K. Palakit, K. Duangsathaporn, P. Sanguantham and P. Prasomsin. 2007. Decadal scale droughts over northwestern Thailand over the past 448 years: links to the tropical Pacific and Indian Ocean sectors. Climate Dynam. 29:63-71.

Chowdhury, K. A. 1939. The formation of growth rings in Indian trees-I. Indian Forest Rec. pp. 1-39.

Chowdhury, K. A. 1940. The formation of growth rings in Indian trees-II. Indian Forest Rec. pp. 41-57.

Chowdhury, K. A. 1964. Growth-rings in tropical trees and taxonomy, The J. Indian Bot. Soc. 43:334-343.

Cook, E. R. 1985. A time series analysis approach to tree ring standardization. Dissertation, University of Arizona, Tucson, AR, USA. Coster, C. 1927. Zur anatomie und physiologie der zuwachszonen und jahresringvildung in den Tropen, Annales d. Jard.botanique de Buitenzorg 37:49160.

Cook, E. R. 1987. The decomposition of tree-ring series for environmental studies. Tree Ring Res. 47:37-59.

Coster, C. 1927. Zur anatomie und physiologie der zuwachszonen und jahresringvildung in den Tropen. Annales d. Jard.botanique de Buitenzorg. 37:49-160.

D'Arrigo, R. D. and G. C. Jacoby. 1989. Reconstructed Northern Hemisphere 
annual temperature since 1671 based on high-latitude tree-ring data from North America, Climatic Change. J. Climatol. 14:39-44.

D'Arrigo, R. D., R. Wilson, J. Palmer, P. Krusic, A. Curtis, J. Sakulich, S. Bijaksana, S. Zulaikah and L. O. Ngkoimani. 2006. Monsoon drought over Java, Indonesia, during the past two centuries. Geophys. Res Lett. 33: L04709, doi:10.1029/2005GL025465.

Fritts, H. C. 1976. Tree Rings and Climate. Academic Press, London. pp. 567.

Gamble, J. S. 1902. A Manual of Indian Timbers, Dehradun. pp.457.

Holmes, R. L. 1983. A computer assisted quality control in tree-ring dating and measurement; Tree Ring Bull. 43:6978.

Holmes, R. L. 1992. Program ARSTAN (Version B-1992), Laboratory of Tree-Ring Research, University of Arizona, Tucson, USA.

Pant, G. B. and H. P. Borgaonkar. 1983. Growth rings of teak trees and regional climatology (An ecological study of Thane region). In: L. R. Singh, S. Singh, R. C. Tiwari and R. P. Srivastava (Eds). pp. 153-158. 'Environmental Management', Geog. Soc. Allahabad, India.

Priya, P. B. and K. M. Bhat. 1998. False ring formation in teak (Tectona grandis L.f.) and the influence of environmental factors. Forest Ecol. Manag. 108:215-222.

Pumijumnong, N. and W. K. Park. 1999. Vessel chronologies from Teak in Northern Thailand and their climatic signal. IAWA. 20:285-294.
Ramesh, R., S. K. Bhattacharyya and G. B. Pant. 1989. Climatic significance of 8 $\mathrm{D}$ variations in a tropical tree species from India. Nature 337:149-150.

Ranjit, R. J. 2007. Biodiversity of the Western Ghats- An overview; Wildlife Institute of India, Dehradun.

Shah, S. K, A. Bhattacharyya and V. Chaudhary. 2007. Reconstruction of June-September precipitation based on tree-ring data of teak (Tectona grandis L.) from Hoshangabad, Madhya Pradesh, India. Dendrochronol. 25:5764.

Somaru, R., H. P. Borgaonkar and A. B. Sikder. 2008. Tree-ring analysis of teak (Tectona grandis L. f.) in Central India and its probable linkage with moisture fluctuation: A case study. J. Earth System Sci. 117:637-645.

Stokes, M. A. and T. L. Smiley. 1968. An introduction to tree-ring dating; The University of Chicago Press, Chicago.

Wigley, T. M. L., K. R. Briffa and P. D. Jones. 1984. On the average value of correlated time series, with applications in dendroclimatology and hydrometeorology. J. Climate Appl. Meteorol. 23:201-213.

Wood, M. L. 1996. Synoptic dendroclimatology in the upper Narmada river basin- an exploratory study in Central India. MS thesis, University of Arizona.

Yadav, R. R. and A. Bhattacharyya. 1996. Biological inferences from the growth climate relationship in teak from India. Proc. Indian Acad. Sci. B. 62:233-238. 